Presented at the ANS Spectrum 2002 meeting Reno, NV, August 6, 2002

\title{
WASTE GLASS MELTER PROCESS MONITORING WITH MILLIMETER WAVES
}

\author{
P. P. Woskov \\ Plasma Science and Fusion Center \\ Massachusetts Institute of Technology \\ Cambridge, MA 02139 \\ 617-253-8648
}

\author{
S. K. Sundaram \\ Pacific Northwest National \\ Laboratory \\ Richland, WA 99352 \\ 509-373-6665
}

\author{
William E. Daniel, Jr. \\ Westinghouse Savannah River \\ Company \\ Aiken, SC 29808 \\ 803-819-8463
}

\section{ABSTRACT}

Millimeter-wave technologies can provide novel and reliable on-line monitoring capability for many important parameters inside nuclear waste glass melters including temperature, emissivity, density, and viscosity. The physical and analytical basis for millimeter-wave monitoring of molten glass is presented here along with initial experimental results. Tests were carried out at a frequency of $137 \mathrm{GHz}(2.19 \mathrm{~mm})$ with ceramic waveguides at temperatures up to $1500^{\circ} \mathrm{C}$. The ability to resolve emissivity and temperature was demonstrated. Cold cap temperature profile measurements have been obtained in a pilot scale melter using a rotating waveguide. Also, the capability to monitor viscosity over a range of 20 to 2000 Poise was shown for a Hanford waste glass.

\section{INTRODUCTION}

Existing and planned nuclear waste glass melters lack sophisticated diagnostics due to the hot, corrosive, and radioactive environments of these melters. This is a significant shortcoming that increases costs and risks of on going and future vitrification efforts at Savannah River, Hanford, and elsewhere. Without process control diagnostics the Defense Waste Processing Facility (DWPF) and current planned melters operate by a feed forward process control scheme that relies on predictive models with large uncertainties. The ability to increase production and waste loading is limited by the bounds of the operating envelope of the feed forward control scheme. Also operations at DWPF have shown these melters are susceptible to anomalies such as foaming and combustion gas build up, which can seriously disrupt operations. Implementing sophisticated diagnostics would reduce uncertainties and allow some degree of feedback process control, which would increase waste loading to theoretical limits and prevent anomalies. Significant cost savings would be realized in improved production efficiencies, reduced storage volumes, and reduced risks.

\section{MILLIMETER-WAVE TECHNOLOGIES}

The millimeter-wave (MMW) range (10 - $0.3 \mathrm{~mm})$ of the electromagnetic spectrum is ideally suited to monitoring applications in the hot, corrosive, and radioactive melter environments. These wavelengths are long enough to penetrate optical/infrared obscure views through dust, smoke, and surface deposits, yet short enough for spatially resolved point and profile measurements. These wavelengths also allow the use of high-temperature corrosion-resistant refractory materials for fabrication of efficient optics and waveguides for use inside the melter. Remote location of all sensitive electronics beyond the radioactive environment is made possible with waveguides. Consequently, MMW technology would be highly reliable in the environment of a nuclear waste glass melter.

Many parameters critical to waste glass processing can be monitored by millimeter-wave methods [1]. Table 1 lists these parameters with the corresponding millimeter-wave effect and technology used. Glass temperature and cold cap temperature profile measurements have been demonstrated in pilot scale arc furnace [2] and melter facilities [3]. Measurements of glass reflectivity, density, viscosity, and fluctuations at molten temperatures have all been demonstrated in the laboratory. Exciting new potential measurement capability for which no monitoring technology yet exists may be possible for plenum gas temperature and liquidus crystal formation. Furthermore, significant melter access is not a necessary requirement because many of these MMW diagnostics could be combined to make use of a single small port for the waveguide access into the melter.

\section{ANALYTCAL BASIS}

The measurement of most of the parameters listed in Table I can be obtained by the millimeter-wave instrument configuration illustrated in Figure 1. A sensitive heterodyne receiver receives and transmits MMW signals to and from the glass via a quasi-optical arrangement using waveguide and optics to interface the receiver field of view with the glass inside of the melter. The waveguide for guiding the MMW signals inside the 
Presented at the ANS Spectrum 2002 meeting Reno, NV, August 6, 2002

TABLE I

Demonstrated and Potential Melter Monitoring with Millimeter-Waves

\begin{tabular}{|c|c|c|c|}
\hline Process Parameter & Measured Effect & MMW Technology & Status \\
\hline Glass temperature & Glass thermal emission & $\begin{array}{l}\text { Receiver with ceramic } \\
\text { waveguide }\end{array}$ & Demonstrated in field \\
\hline $\begin{array}{l}\text { Cold cap temperature } \\
\text { profiles }\end{array}$ & $\begin{array}{l}\text { Cold cap thermal } \\
\text { emission }\end{array}$ & $\begin{array}{l}\text { Receiver with scanning } \\
\text { waveguide }\end{array}$ & “ \\
\hline $\begin{array}{l}\text { Glass emissivity/ } \\
\text { conductivity }\end{array}$ & Reflection amplitude & $\begin{array}{l}\text { Thermal return } \\
\text { reflection receiver }\end{array}$ & Demonstrated in lab \\
\hline Glass density & Reflection phase & $\begin{array}{l}\text { Coherent reflection } \\
\text { receiver }\end{array}$ & “ \\
\hline Viscosity & Reflection phase rate & $\begin{array}{l}\text { Time resolved coherent } \\
\text { reflection receiver }\end{array}$ & “ \\
\hline Glass flows/fluctuations & Reflection fluctuations & $\begin{array}{l}\text { Fast time resolved } \\
\text { coherent reflection } \\
\text { receiver }\end{array}$ & “ \\
\hline Plenum temperature & Gas thermal emission & $\begin{array}{l}\text { Submillimeter-wave } \\
\text { receiver }\end{array}$ & To be developed \\
\hline $\begin{array}{l}\text { Instantaneous cold cap } \\
\text { temperature profiles }\end{array}$ & $\begin{array}{l}\text { Cold cap thermal } \\
\text { emission }\end{array}$ & $\begin{array}{l}\text { 2-D Imaging array } \\
\text { receiver }\end{array}$ & “ \\
\hline $\begin{array}{l}\text { Liquidus crystal } \\
\text { formation }\end{array}$ & $\begin{array}{l}\text { High resolution } \\
\text { reflection phase }\end{array}$ & $\begin{array}{l}\text { High resolution coherent } \\
\text { reflection receiver }\end{array}$ & “ \\
\hline $\begin{array}{l}\text { Noble metals } \\
\text { accumulation }\end{array}$ & Reflection amplitude & $\begin{array}{l}\text { Thermal return } \\
\text { reflection with } \\
\text { immersed waveguide }\end{array}$ & “ \\
\hline
\end{tabular}

melter is made from a high temperature refractory material such a mullite or Inconel. A window seals the waveguide outside the melter to allow pressure control when the waveguide is immersed into the glass for density and viscosity measurements. A beamsplitter reflects part of the MMW thermal emission to a side mirror for a thermal return reflection (TRR) measurement of glass emissivity.

\section{A. Temperature and Emissivity}

The temperature and emissivity are determined by measurements of the thermal radiation and its refection from the hot glass. The receiver can be precisely calibrated for temperature measurement at the waveguide window by inserting a known blackbody temperature reference at this location. Determining the glass temperature and emissivity from the effective temperature at the window (designated as $T_{\text {eff }}$ ) requires taking into account all the quasi-optical transmission losses, sources of thermal emission, and reflections between the receiver and glass.
The relationship between the measured effective temperature at the waveguide window and the glass temperature and emissivity when the TRR mirror is blocked and the receiver does not reflect any signal is given by:

$$
T_{e f f}=\varepsilon_{w g} T_{w g}+\tau_{w g} \varepsilon_{s} T_{s}+r_{s} \tau_{\kappa} \tau_{w g} \varepsilon_{w g} T_{w g}
$$

where the first term on the right is the signal from the waveguide as determined by its emissivity, $\varepsilon_{w g}$, and temperature, $T_{w g}$, the second term is the signal from the glass as determined by its emissivity, $\varepsilon_{s}$, temperature, $T_{s}$, and transmission through the waveguide, $\tau_{w g}$, and the third and finial term is the reflection of the waveguide signal directed toward the glass, as determined by the glass reflectivity, $r_{s}$, the optical coupling to the waveguide, $\tau_{\kappa}$, and transmission back to the receiver. The glass emissivity and reflectivity are related by:

$$
r_{s}=\left(1-\varepsilon_{s}\right)
$$




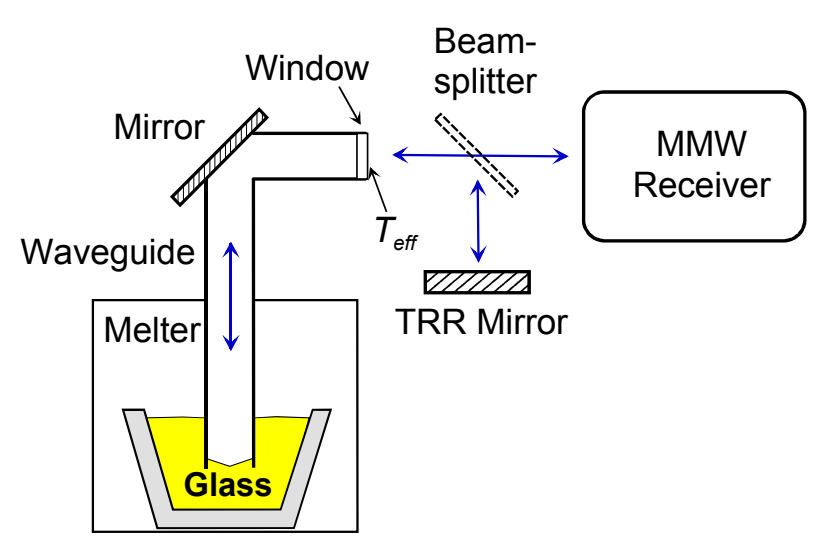

Figure 1. Instrument configuration for millimeter-wave glass melter measurements

When the receiver reflects some of the signal and is aligned to form a resonator with the viewed glass surface, the measured effective temperature is modified from Eq. (1) as:

$$
T_{e}=\frac{T_{e f f}}{1-\tau_{w g}^{2} \tau_{b s}^{2} \tau_{\kappa} r_{s} r_{i}}
$$

where $\tau_{b s}$ is the beamsplitter transmission and $r_{i}$ is the receiver reflection factor. Eq. (3) reduces to Eq. (1) when the receiver reflectivity goes to zero $\left(r_{i}=0\right)$ as expected.

The glass reflectivity (and consequently the glass emissivity through Eq. (2)) is determined by taking the ratio of the measured temperatures with and without the TRR mirror blocked. The glass reflectivity is given by:

$$
r_{s}=\frac{1}{\tau_{w g}^{2} \tau_{\kappa} A}\left(1-\frac{T_{e}}{T_{e}^{\prime}}\right)
$$

where $T_{e}$ is the effective temperature when the TRR mirror is blocked and $T_{e}^{\prime}$ is the effective temperature when the TRR mirror is unblocked. The parameter A is given by:

$$
A=\tau_{m} r_{b s}^{2}+r_{i} \tau_{b s}^{2}\left(1-\frac{T_{e}}{T_{e}^{\prime}}\right)
$$

where $\tau_{m}$ is the optical coupling factor for the TRR mirror to the waveguide. The optical coupling parameters, beamsplitter transmission/reflection, receiver reflection, and waveguide transmission are all instrumentation constants and can all be determined independently when the MMW instrumentation is initially setup on a melter.

\section{B. Density and Viscosity}

Density and viscosity are obtained by monitoring the leaked local oscillator signal from the receiver, which is reflected from the glass. This is a coherent signal so that the detected amplitude depends on the phase of the reflected signal. The phase depends on the path length to and from the glass surface and is given by:

$$
\delta=4 \pi \frac{\Delta y}{\lambda}
$$

where $\Delta y$ is the change in the round trip path difference and $\lambda$ is the millimeter signal wavelength. A change in the round trip path difference of $1 / 2 \lambda$ (or a glass displacement of $1 / 4 \lambda$ ) corresponds to a phase shift of $2 \pi$ varying the signal through a complete cycle of peak to minimum and back. In optics terminology this is called a fringe.

An example of millimeter-wave fringe shift detection corresponding to a small displacement of a surface relative to the receiver is shown in Figure 2. The setup used for this data is similar to that shown in Fig. 1 except the view is of a fixed surface inside a furnace. The reflected MMW signal at a wavelength of $2.19 \mathrm{~mm}$ $(137 \mathrm{GHz})$ clearly shows cycling through fringes as the waveguide is heated to over $1400^{\circ} \mathrm{C}$. The slightly over 4.5 fringes plotted corresponds to a change in distance to the viewed surface of $\sim 2.7 \mathrm{~mm}$, which is consistent with the expected expansion of the $\sim 38 \mathrm{~cm}$ long section of the mullite waveguide that was heated.

Density measurement in molten glass would be accomplished at constant temperature by immersing the waveguide, pressurizing, and recording the glass displacement. The ratio of the waveguide pressure in units of water displacement to the displacement of the glass is by definition the glass density. If the molten

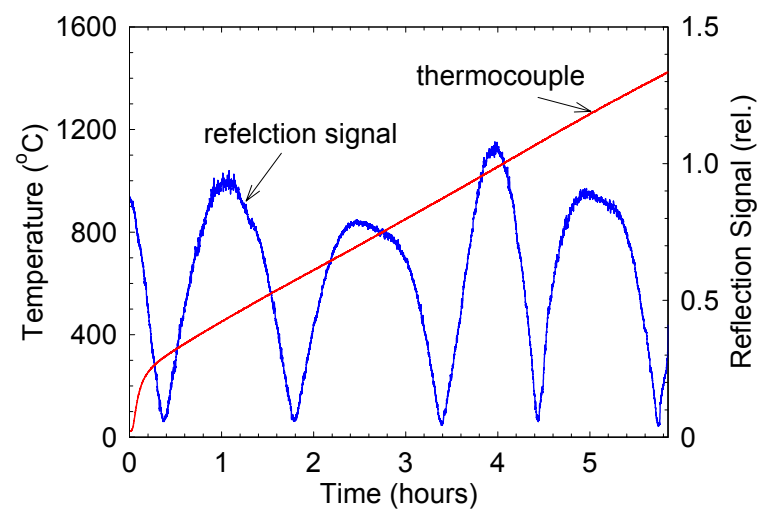

Figure 2. $137 \mathrm{GHz}$ millimeter-wave fringe shifts as a heated mullite waveguide expands. 
glass crucible is small there would be a correction for finite volume effects. Since sensitivity to glass displacement is very high, the potential density measurement sensitivity in large volumes is also very high (on the order of one part in 1000), which could be the basis for detecting subtle phase changes such a liquidus.

Viscosity is determined by measuring the time rate of change of the fluid glass surface position in response to a pressure transient in the waveguide. The relation between flow rate and viscosity in the waveguide is analogous to the Ubbelohde or Cannon Fenske type capillary viscometers where the relationship between kinematic viscosity and the time for flow, $\Delta t$, between two fixed positions in the waveguide is given by [4]:

$$
v=C \Delta t
$$

where $\mathrm{C}$ is a constant that depends on the waveguide dimensions, its immersion depth, pressure used, and other instrumentation constants.

The dynamic viscosity is related to the kinematic viscosity by:

$$
\eta=v \rho
$$

where $\rho$ is the glass density, which is also obtained in the waveguide displacement measurement. The millimeterwave viscometer therefore can monitor dynamic viscosity by the conventional capillary flow method where the capillary in this case is the MMW waveguide.

\section{EXPERIMENTAL WORK}

Development activities have been undertaken at a wavelength of $2.19 \mathrm{~mm}(137 \mathrm{GHz})$ with a heterodyne receiver adapted for both passive and active probing measurements. Experiments have been carried out in a laboratory electric furnace at MIT and at the EV-16 melter at Clemson Environmental Technology Laboratory (CETL).

In the first phase of work refractory waveguides suitable for use in high temperature oxidizing environments were designed and tested. Overmoded (dimensions large relative to the wavelength) waveguides of Inconel 690 and mullite $\left(3 \mathrm{Al}_{2} \mathrm{O}_{3} \cdot 2 \mathrm{SiO}_{2}\right)$ with transmission efficiencies $>90 \%$ were demonstrated and used for both noncontact and immersed experiments. This work suggests that almost any refractory material that can be fashioned into a hollow pipe could be used as a MMW waveguide inside a melter. These waveguides propagate the $\mathrm{HE}_{11}$ mode that requires a smooth surface in dielectric materials such a ceramics, but corrugated walls in conductors such as Inconel [5].

Labortaory tests validated the MMW methods for temperature, emissivity, density, and viscosity. Also some preliminary basic MWW data was obtained of important melter refractory materials. An illustration of the TRR method to determine emissivity of $\mathrm{K} 3$ refractory material at $1500^{\circ} \mathrm{C}$ is shown in Figure 3. A flat sample of $\mathrm{K} 3$ refractory material was viewed at the end of the waveguide inside the furnace. The TRR mirror was repetitively blocked and unblocked to produce the plot shown. The ratio of the temperatures $T_{e}$ and $T_{e}^{\prime}$ was used in Eqs. 4 and then with Eq. 2 to determine an emissivity of about $\sim 0.5$ for $\mathrm{K} 3$ at $137 \mathrm{GHz}$. This is much lower than a corresponding measurement for alumina which was found to have an emissivity of $\sim 0.8$. The TRR method will be a valuable new approach for noncontact thermal analysis of materials at high temperatures.

\section{RESULTS}

The capability for noncontact cold cap temperature profile measurements and the reliability of MMW technology in a melter environment was demonstrated on the engineering scale melter EV-16 at CETL. Cold cap diagnostics were carried out during a test campaign processing a glass composition containing high $\mathrm{Ca}-\mathrm{F}-$ calcined waste representative of the Idaho site. The MMW receiver was set up beside the melter and viewed inside through a horizontal, 22 in $(55.9 \mathrm{~cm})$ long, 1.875 in $(4.76 \mathrm{~cm})$ diameter mullite waveguide with an Inconel $690,45^{\circ}$ miter mirror on the inside end. Surface temperature profiles could be mapped out by rotating the waveguide and sliding it in and out of the melter plenum space. The MMW hardware operated reliably 24 hours a day for the entire test period lasting over a week.

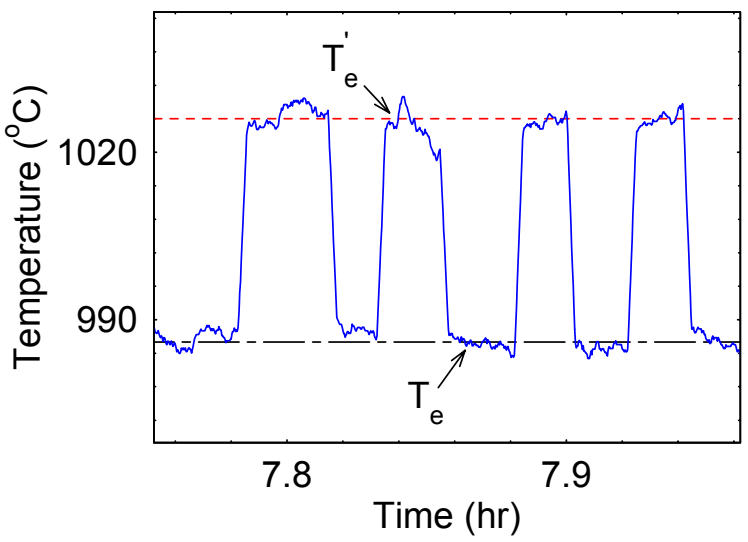

Figure3. Illustration of TRR method with K3 sample at $1500^{\circ} \mathrm{C}$. 
The TRR method is generally not applicable nor necessary for profile measurements inside a melter. This is because the viewed surface is not generally aligned to return a reflection and the entire environment inside a melter is hot. MMW ray tracing analysis of pyrometer temperature profile measurements inside an arc furnace have shown that the correction for emissivity is generally small even if the emissivity is fairly low [6].

Melter processing dynamics were clearly manifested in cold cap temperature profiles. Drifting cold and hot spots during feeding, hot spots above heated electrodes, and a dramatic cold spot above the spout during pouring were all recorded. Illustrative temperature profiles of the melt surface are shown in Figure 4. The waveguide was rotated to scan the temperature profiles approximately 4.5 inches $(11.4 \mathrm{~cm})$ from the center of the 16-inch $(40.6 \mathrm{~cm})$ square surface. The view at 90 degrees waveguide view direction was straight down and the melt surface extended approximately \pm 40 degrees in either direction. The view beyond this angular waveguide rotation range was up the

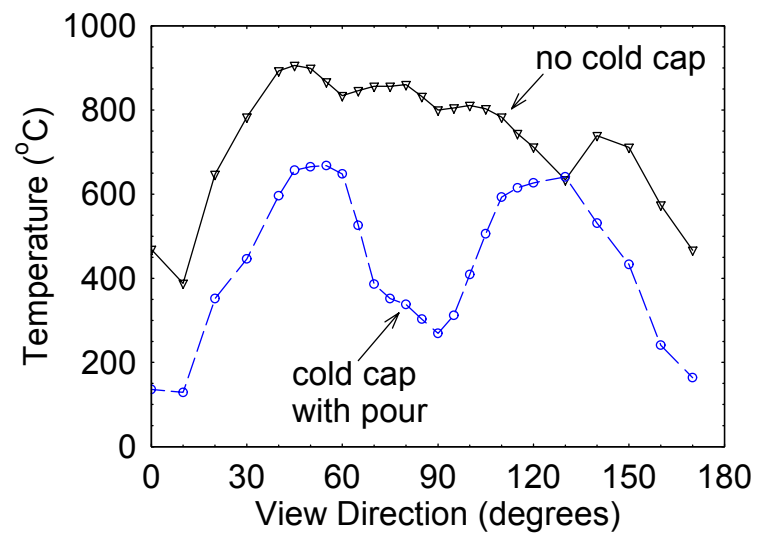

Figure 4. Illustrative surface temperature profiles inside the EV-16 melter without cold cap wit h cold cap during glass pour.

sidewalls. The top plot is of the melt without a cold cap. The temperature profile is higher toward the front because the front electrode was operated at higher power. The lower plot is with a cold cap and during glass pouring from a spot below the center of the melt. The temperature in the center of the cold cap typically dropped by a factor of two or more relative to the edges during each pouring event.

Two dimensional temperature profiles were also obtained by sliding the waveguide horizontally in and out to obtain multiple rotational scans at different horizontal positions. Figure 5 shows such a profile after cold cap burn off. The melter was operated with more power to the front electrode causing a front to back temperature

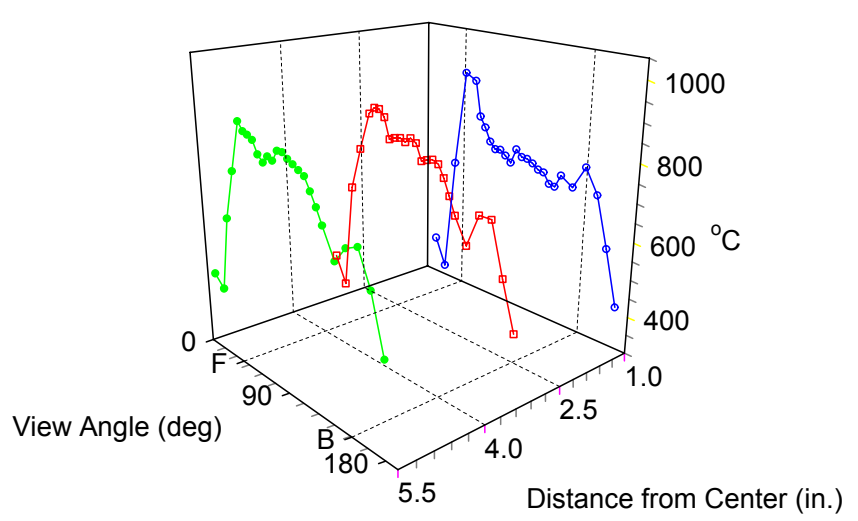

Figure 5. Two dimensional EV-16 Melt surface temperature profile.

gradient. The hot spot above the central front electrode is evident as well as a bump above the middle side electrode. Such surface temperature profile monitoring would be of valuable for balancing feed, melt, and pour rates and to control off gas emissions during continuous melter processing.

Viscosity monitoring capability was demonstrated in small crucible melts at MIT. A linear relationship was established between viscosity and the rate of glass flow inside a waveguide in response to a sudden pressure transient. Actually, two different pressure transients are used to subtract out surface tension effects. Figure 6 shows data for a Hanford high-level waste glass composition (Hanford \#8). The known dynamic viscosity of the glass is plotted as a function of flow time between 0.5 and 1.2-inch water pressure transients. The measured displacement of the glass was much smaller than the equivalent water displacement corresponding to a glass density near 2.7 . Heating the glass from 850 to $1200{ }^{\circ} \mathrm{C}$ the viscosity was varied over a range of approximately 20

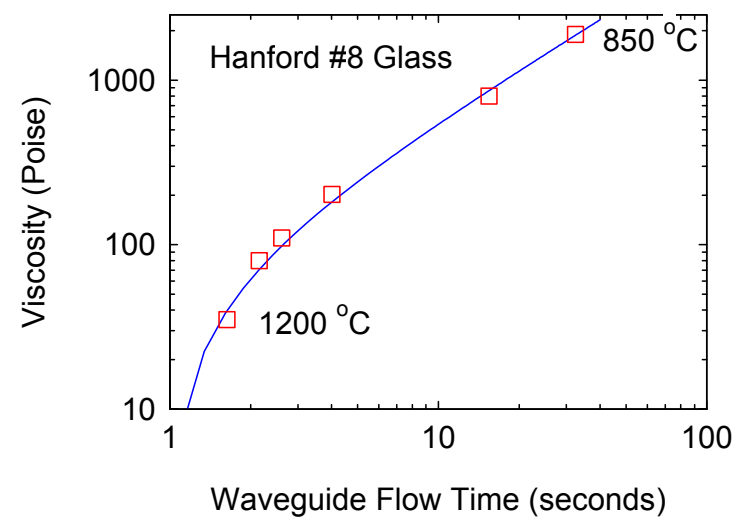

Figure 6. Viscosity versus measured MMW flow time inside a $28.6 \mathrm{~mm}$ diameter mullite waveguide 
to 2000 Poise. The measured rate of glass flow follows the viscosity linearly over this large dynamic range as shown by the plot through the experimental points in Figure 6. Planning is under way to test this MMW viscosity monitoring capability in the field.

\section{ACKNOWLEDGEMENT}

This work was supported by the Environmental Management Science Program, U.S. Department of Energy under grant number DE-FG07-01ER62707.

\section{REFERENCES}

1. P. Woskov, J. S. Machuzak, P. Thomas, S. K. Sundaram, and W. E. Daniel, “ Millimeter-Wave Monitoring of Nuclear Waste- An Overview", MIT PSFC Report \# JA-02-1,
www.psfc.mit.edu/library/02ja/02JA001/02JA00 abs .html, 2002.

2. P. Woskov, D. R. Cohn, D. Y. Rhee, P. Thomas, C. H. Titus, and J. E. Surma, "Active Millimeter-Wave Pyrometer”, Rev. Sci. Instrum., vol. 66, pp.42414248, 1995.

3. S. K. Sundaram, W. E. Daniel, P. Woskov, J. Machuzak, "Cold Cap Monitoring Using MillimeterWave Technology", Proceedings of the American Ceramic Society, April meeting, Indianapolis, 2001.

4. Haake Viscometers, Gebrüber HAAKE GmbH, D7500 Karlsruhe, Germany, 1981.

5. J. L. Doane, Infrared and Millimeter Waves, vol. 13, K. Button Ed., Academic, New York, 1985.

6. S. K. Lee and P. P. Woskov, J. "Pyrometry inside an arc furnace using a ray-tracing correction for surface emissivity", Computer-Aided Materials Design, 4, 99 (1997). 